\title{
ARDVA QVAE PVLCHRA O L'ESFORÇ DE PERPETUAR ELS ESTUDIS CLÀSSICS, MALGRAT TOT
}

\author{
DAVID SOLÉ GIMENO \\ Universitat de Barcelona \\ dsoleg@ub.edu \\ ORCID: 0000-0002-0184-0664 \\ CARLOS PRIETO ESPINOSA \\ Universidade de Lisboa \\ cprieto@edu.ulisboa.pt \\ ORCID: 0000-0001-9133-4636 \\ ANAHí Álvarez AGUADO \\ Universitat de Barcelona \\ anahialvarez@ub.edu \\ ORCID: 0000-0001-9652-9985 \\ AlBA DOMÍNGUEZ CARCELLER \\ Universitat de Barcelona \\ albadominguezcarceller@gmail.com \\ ORCID: 0000-0002-2780-7512
}

En un món cada vegada més (con)centrat i (pre)ocupat pel progrés econòmic, tècnic i científic - ignorant, aquí, l'extens domini que abasta el latent significat de scientia-, l'interès a recordar d'on venim per preguntar-nos cap a on anem resulta, en general, força escàs. Tanmateix, sabem que, inevitablement, des de tots els seus prismes, l'antiguitat grecollatina segueix evocant la seva essència a la nostra quotidianitat: només ens cal ser conscients, en aquests temps tan malauradament particulars, de com el testimoni de Tucídides sobre la pesta atenesa del segle $\mathrm{V}$ aC va servir perquè especialistes en medicina n'extraguessin importants aspectes nosològics. Gràcies a aquesta i a tantes altres evidències - tot i que progressivament negligides - , l'impertorbable llegat de Grècia i Roma deixa empremta en la curiositat de moltes persones, fins al punt que algunes encara gosen emprendre el camí dels estudis clàssics. I tothom que intenta evitar les aportacions de l'antiguitat a qualsevol preu - molts de mal anomenats 'científics' - acaba comprovant que mai no en pot prescindir del tot.

Si bé una precària promoció social i institucional amb prou feines facilita l'interès pel món clàssic als més joves estudiants, el moviment constant (i sovint ardu) dels investigadors i docents de Filologia Clàssica - tots ells, divulgadors a diferents nivells - resulta decisiu per mantenir el grec i el llatí en el lloc que els pertoca. De la mateixa manera que Glaucó, davant la decisió de Sòcrates d'examinar els tres elements que conformen l'ànima, explicita que «les coses 
belles són difícils» ( $\chi \alpha \lambda \varepsilon \pi \grave{\alpha} \tau \grave{\alpha} \kappa \alpha \lambda \alpha$, Pl. R. 435c), així nosaltres (investigadors, docents, discents $\mathrm{o}$, simplement, interessats en el món grecoromà) fem front a la dura però alhora bella - preciosa - tasca de seguir posant en vàlua tot el solatge del qual l'antiguitat clàssica ens ha fet hereus. D'aquesta manera, tenim l'oportunitat d'esdevenir una generació que s'esforci a optimitzar tant com sigui possible la transmissió d'aquest tresor i procurar, per tant, que tothom pugui reflexionar sobre el valor de consignes com la que encapçala aquest volum: ardua quae pulchra. Es tracta, en aquest cas, d'una adaptació llatina de la cèlebre cita platònica que hom troba a Erasme de Rotterdam (Adagia 1012), humanista que il·lustrà, de la millor de les maneres, la metamorfosi que pot arribar a generar en l'ésser humà el coneixement de Grècia i Roma.

Les pàgines que vindran a continuació reflecteixen d'una manera fefaent com hi ha quelcom que es mou - i molt - en els primers estadis de la recerca dels estudis clàssics a nivell espanyol. Efectivament, el present volum de l'Anuari de Filologia. Antiqua et Mediaeualia (AFAM) és fruit d'algunes de les nombroses contribucions que diversos investigadors novells en Filologia Clàssica van presentar durant el VII Congrés Nacional Ganimedes. Organitzat anualment en diverses ciutats estatals per l'Asociación Ganimedes de Investigadores Noveles de Filología Clásica, des de la Facultat de Filologia de la Universitat de Barcelona vam entomar el repte d'acollir-ne la setena edició els dies 13, 14 i 15 de març del 2019. Estudiants de doctorat i màster de tot el país (i també de fora) hi exposaren les seves primeres recerques en cadascun dels àmbits que suposen els estudis clàssics: lingüística, literatura i crítica textual gregues i llatines, tradició clàssica i humanisme. Tals aportacions testimonien, novament, no només la complexitat de la nostra disciplina, sinó també un rigor, una passió i un compromís a mantenir-la i posar-la de relleu.

A banda de les diverses comunicacions i pòsters que aquest encontre va acollir, també vam tenir el plaer d'escoltar les ponències de tres catedràtics de de les Seccions de Filologia Grega i Filologia Llatina i Lingüística Indoeuropea del Departament de Filologia Clàssica, Romànica i Semítica de la Universitat de Barcelona. Des de la vessant de la Lingüística Indoeuropea, el Dr. Ignasi-Xavier Adiego Lajara va parlar de L'estudi de l'antroponímia minorasiàtica: balanç $i$ perspectives; en termes de Filologia Grega, el Dr. Jaume Pòrtulas Ambròs va presentar Reflexions velles i noves sobre la Ilíada; i, finalment, des de l'àmbit de la Filologia Llatina, el Dr. José Luis Vidal Pérez va exposar El poder de la palabra en Roma: poder y seducción.

Amb tot plegat, el VII Congrés Nacional Ganimedes va gaudir d'una molt bona rebuda i va arribar a ser una realitat gràcies al màxim esforç i les millors intencions del comitè organitzador, conformat per doctorands de les Seccions suara citades: Anahí Álvarez Aguado, Anna Cortadelles i Adzerias, Eloi Creus Sabater, Alba Domínguez Carceller, Rubén José García Muriel, Elena Martínez Rodríguez, Carlos Prieto Espinosa, Víctor Sabaté Vidal, David Solé Gimeno i Ignasi Vidiella Puñet. També cal reconèixer l'excel-lent i no gens fàcil tasca del 
comitè científic, encarregat d'avaluar les propostes de participació rebudes per a l'ocasió: Daniel Ayora Estevan, Ibor Blázquez Robledo (president, aleshores, de l'associació), Álvaro Cancela Cilleruelo, Sandra Cruz Gutiérrez, Marina Díaz Marcos, Pedro Fernández Requena, María Flores Rivas, Marina Míguez Lamanuzzi, Cynthia Pérez Carrillo, Isaac Pérez Hernández, Soraya Planchas Gallarte, Víctor Sabaté Vidal i Carlos Sánchez Pérez. Indispensable, també, fou el recolzament de tots els organismes i institucions que van dipositar la seva confiança en el nostre equip i que van contribuir a la celebració del congrés amb generoses aportacions monetàries i materials. Ens referim a la pròpia Universitat de Barcelona (concretament, el Vicerectorat de Doctorat i Promoció de la Recerca; el Vicerectorat d'Estudiants i Política Lingüística; el Deganat de la Facultat de Filologia; el Departament de Filologia Clàssica, Romànica i Semítica; i el Programa de Doctorat d'Estudis Lingüístics, Literaris i Culturals), a la Sociedad Española de Estudios Clásicos i a la Societat Catalana d'Estudis Clàssics. A més, els organitzadors vam comptar amb el suport logístic del Grup d'Innovació Docent Cinestèsia i d'Anna Agramunt, editora de la pàgina web del congrés.

Volem aprofitar per agrair les aportacions de totes aquestes persones, així com també dels assistents i participants, que van aconseguir que el congrés es convertís en una autèntica celebració d'enriquiment - científic i humà - entre les fornades més joves del món dels estudis clàssics. Com dèiem fa un moment, algunes de les aportacions que els joves investigadors van presentar durant aquelles jornades s'ofereixen, ara, en aquest monogràfic, convertides en articles científics, que han estat sotmesos a un procés de revisió per parells cecs. També apreciem, doncs, la feina feta per part dels revisors dels subsegüents articles, ja que n'han acabat d'assegurar la qualitat i el rigor científics exigibles. De la mateixa manera, agraïm la plena disposició de L'AFAM a recollir, des de bon principi, les contribucions del VII Congrés Nacional Ganimedes en aquest número. Finalment, d'una manera especial, volem donar les gràcies a Ignasi Vidiella Puñet que, essent president del comitè organitzador durant el congrés i membre del comitè editorial en un començament, va ajudar d'una manera significativa a les primeres i decisives etapes de confecció d'aquest volum.

Barcelona, setembre de 2021 
